Far Eastern Entomologist

\begin{tabular}{lll}
\hline Number 424: 14-20 & ISSN 1026-051X (print edition) & February 2021 \\
\hline
\end{tabular}

https://doi.org/10.25221/fee.424.2

http://zoobank.org/References/D23DBC30-318E-4CEE-8EE9-CA83F4249903

\title{
A NEW SPECIES OF GENUS ANOMALA SAMOUELLE, 1819 (COLEOPTERA: SCARABAEIDAE, RUTELINAE) FROM CHINA
}

\author{
F. L. Wang \\ Engineering Research Center for Forest and Grassland Disaster Prevention and Reduction, \\ Mianyang Normal University, 166 Mianxing West Road, Mianyang, Sichuan 400000, P. R. \\ China.E-mail: 531609816@qq.com
}

Summary. Anomala huangjianbini sp. n. is described from Chongqing, Fujian, Guangxi, Hunan, and Sichuan of China. Habitus and male genitalia of new species and A. vitalisi Ohaus, 1914 are illustrated for purposes of comparison. A distribution map of both species is also provided.

Key words: beetles, Anomalini, taxonomy, new species, distribution, map, Asia.

Ф. Л. Ванг. Новый вид рода Anomala Samouelle, 1819 (Coleoptera: Scarabaeidae, Rutelinae) из Китая // Дальневосточный энтомолог. 2021. N 424. C. 14-20.

Резюме. Из Чунсина и китайских провинций Сычуань, Фуцзянь, Гуаньси и Хунань описан Anomala huangjianbini sp. n. Для сравнения даны фотографии тела и гениталий самца нового вида и близкого к нему A. vitalisi Ohaus, 1914. Также приведена карта распространения этих двух видов.

\section{INTRODUCTION}

Ohaus (1914) illustrated male genitalia of Anomala vitalisi Ohaus, 1914 from Vietnam with long forked ventral plate (Ohaus 1914: 207, fig. 207; Paulian, 1959: 58, figs 233-234), however, P. Lin illustrated male genitalia of "A. vitalisi" from Southern China with short forked ventral plate (Lin 2002: 410, fig. 27-582).

This contradiction prompted the author to dissect several male specimens from Chongqing, Fujian, Guangxi, Hunan and Sichuan, and found that their short ventral plate of male genitalia is quite stable which identical with Lin (2002) rather than Ohaus (1914). As result a new species is described below.

\section{MATERIAL AND METHODS}

Morphological terminology used in this study was introduced by Zorn (2007). Type specimens are bearing the following labels: 1. HOLOTYPUE or PARATYPUE; 2. Anomala [species name], des. FL-Wang, 2020; 3. Collecting information.

The material examined are deposited in the following collections: MYNU - Mianyang Normal University, Mianyang, Sichuan, China; CFLW - private collection of Fa-Lei Wang, 
Chongqing, China; CMZZ - private collection of Ming-Zhi Zhao, Zhuhai, China; CCCC private collection of Chang-Chin Chen, Tianjin, China; SCAU - South China Agricultural University, Guangzhou, China.

\section{TAXONOMY}

Anomala huangjianbini Wang, sp. n.

http://zoobank.org/NomenclaturalActs/009C7E94-C524-4474-8672-BEA41ACD8F80

Figs 1, 2, 7-10, 13-16, 19-22, 25-27

TYPE MATERIAL. Holotype - male, China: Sichuan Province, Yaan City, Xingyang County, Longcanggou, 18-20.VI 2016, leg. Hao Xu \& Jian-Yue Qiu (MYNU). Paratypes: same data as the holotype, $1 \hat{0}, 11$, (CFLW); Chongqing City, Nanchuan District, Jinfoshanshan Mountain, h=1.200 m, 28.V 2017, 2ㅇ, leg. Fa-Lei Wang (CFLW); Chongqing City, Jiangjin District, Simianshan Mountain, 28.V 2017, 29, leg. Hao Xu \& Jian-Yue Qiu (CFLW); Fujian Province, Nanping City, Yanping District, Xiyuanxiagu Canyon, $\mathrm{h}=480 \mathrm{~m}$,

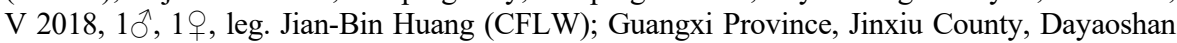

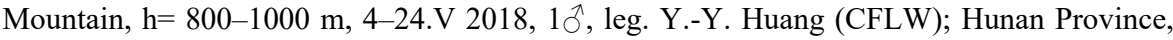
Chenzhou City, Yizhang County, Mangshan Mountain, 11.V 2016, 1ð , leg. Zhao-Yang Tang (CFLW); Guangdong Province, Qingyuan City, Yangshan County, Guangdongdiyifeng Mountain, h=1600 m, 4.VI 2019, 19, leg. Jian-Yue Qiu (CFLW). CHINA: Sichuan, Ya'an City, near Longcanggou Forest Park, light trap, 8.VI 2019, 1ðึ, 7ㅇ, leg. Zheng Zhou \& Li-

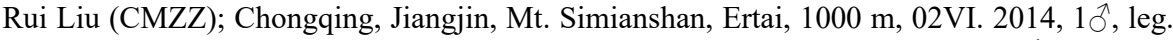
Hao Xu (CMZZ); Guangxi, Jinxiu, Dayaoshan, Gubaotun, 850 m, 11.V 2017, 1ठ, leg. J.-T. Zhao (CCCC); Guangdong, Nanling Nature Reseve, 3-5.V 2011, 1क, Lang-Jie Chen leg. (SCAU); Fujian, Longyan, Mt. Tiangongshan, $800 \mathrm{~m}$, light trap, 28.III 2019, 20, leg. YuChen Zheng (CMZZ); Fujian Province, Quanzhou City, Dehua County, Shuikou Town, Mt. Shiniushan, Geyao, $1100 \mathrm{~m}, 16 . \mathrm{IV}$ 2020, 50, 3잉 leg. Yu-Chen Zheng (CMZZ); the same locality, 17.IV 2020, 5万, 4ㅇ, leg. Yu-Chen Zheng (CMZZ); the same locality, 18.IV 2020, $2 \hat{\jmath}, 3$, leg. Yu-Chen Zheng (CMZZ); the same locality, 14.V 2020, 10, 4우, leg. Yu-Chen Zheng (CMZZ); Fujian Province, Quanzhou City, Dehua County, Shuikou Town, Xiqianduan, $640 \mathrm{~m}$, 18.IV 2020, 8잉 leg. Yu-Chen Zheng (CMZZ); the same locality, 19.IV 2020, 3 , leg. Yu-Chen Zheng (CMZZ); Fujian Province, Wuyishan, Wuyishan Nature Reserve, light trap, 3.V 2020, 19, leg. Shun-Sheng Li (CMZZ).

DESCRIPTION. Male, holotype (Figs 1-12). Length: $11.2 \mathrm{~mm}$, width: $8.3 \mathrm{~mm}$. Body elongate ovoid, moderately convex in profile. Head (except antenna), pronotum, scutellum, legs, and ventral surface deep metallic green with bronze reflections in different angles, apex of protibial without green color; antennal club yellowish brown, footstalk blackish brown.

Head. Clypeus subtrapezoidal, 0.5 times as long as wide, board rounded, anterior margin strongly reflexed, surface with coarse and reticulate punctures; fronto-clypeal suture complete; frons with deeply and reticulately punctate on apical half, punctures adjacent to each other, partly coalescing and forming small transverse striae, with several hairs; interocular distance equals 0.67 times the maximum transverse head width; vertex with dense punctures, sparer in the middle; antennal club longer than footstalks.

Pronotum 1.8 times as wide as long, sides convergent in the middle, posterior $1 / 2$ straight; anterior marginal line nearly completely, posterior marginal line weak in median $1 / 3$, posterior margin broaden in middle, with sparse microscopic punctures; anterior angles and posterior angles acute; disc with densely, largely, and deeply transverse punctures, several punctures 
coalescent, gradually becoming smaller rugoso-punctate or microgroove to the side and angles, a small area around scutellum with largely transverse punctures which are adjacent to each other or integrate into transverse striolation; disc with a distinct longitudinal median line in the middle, striate densely microscopic punctate.
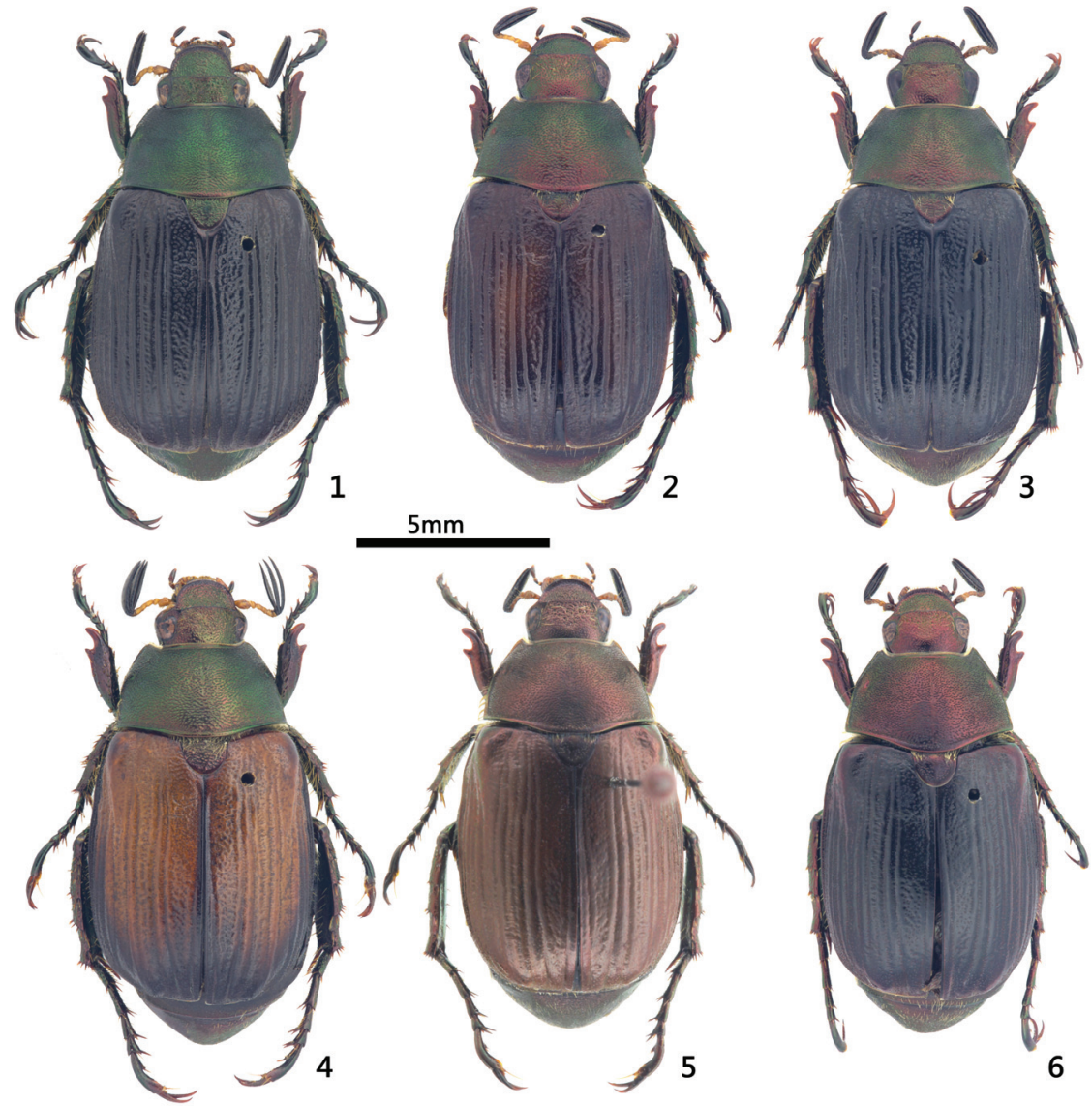

Figs 1-6. Anomala spp., habitus, male. 1-4-A. huangjianbini sp. n.: 1 - holotype (from Sichuan); 2 - paratype (from Fujian); 3 - paratype (from Hunan); 4); 4 - paratype (from Guangxi); 5, 6-A. vitalisi (from Yunnan).

Scutellum 1.5 times as wide as long, apex well rounded; surface densely transverse punctate, punctures partly coalescent and rugoso-punctate, with a smooth area in the middle and lateral margins smooth.

Elytra 0.9 times as wide as long, widest in anterior 2/5; elytra regularly striate-sulcate, striate punctures large, sometimes adjacent to each other, intervals convex, with tiny and rather spare punctures; subsutural interstice broad, gradually narrowed in posterior $1 / 2$, with rather large and deep punctures, almost all the punctures adjacent to each other horizontally; humeral umbones distinct and smooth, without punctures; lateral margins coarsely, epipleuron flat after humeral umbones. 

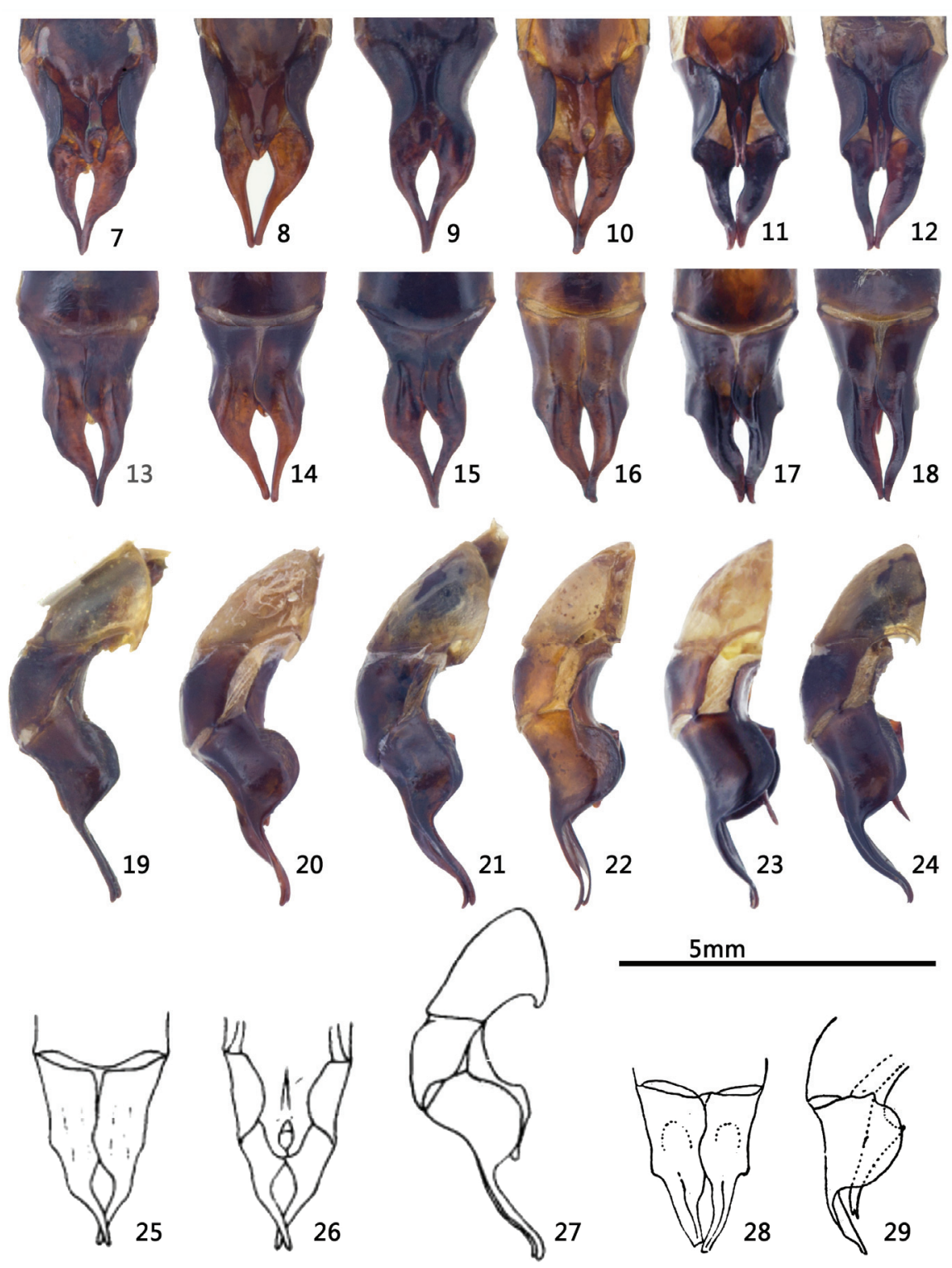

$5 \mathrm{~mm}$

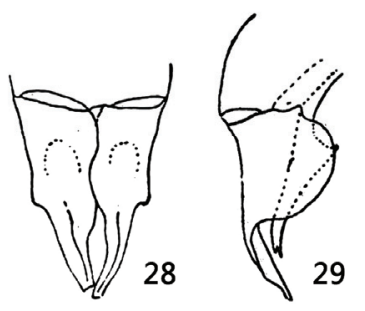

Figs 7-29. Anomala spp., male genitalia. 7, 13, $19-$ A. huangjianbini sp. n. (holotype from Sichuan); 8, 14, $20-A$. huangjianbini sp. n. (from Fujian); 9, 15, $21-A$. huangjianbini sp. n. (from Hunan); 10, 16, 22. - A. huangjianbini sp. n. (from Guangxi); 11, 12, 17, 18, 23, 24 - A. vitalisi (from Yunnan); 25-27 - A. huangjianbini sp. n. (after Lin, 2002); 28, $29-A$. vitalisi (after Ohaus, 1914); 7-12, 26 - ventral view; 13-18, 25, 28 - dorsal view; 19-24, 27, 29 - lateral view from left. 
Propygidium. Densely with transverse punctures, deeply in the middle. Pygidium weakly convex in profile, surface densely transverse punctate, coalescing and forming small transverse striae; surface with slightly dense brown setae, apex longer. Abdominal ventrites with dense oval punctures in the middle, gradually becoming denser transverse punctures to the sides, ventrites with yellow setae, sparer in the middle, denser at sides, setae on ventrites 1 denser.

Legs. Protibia bidentate, terminal tooth prolonged, another tooth sub-rightangle; mesotibia and metatibia clubbed, inner surface with dense yellow hair; protarsal inner claw clefted, the upper branch of the inner protarsal claw small, mesotarsal outer claw slight clefted.

Genitalia as in Figs. 7-10.

VARIABILITY. Body length $11.0-11.9 \mathrm{~mm}$, width $8.1-8.3 \mathrm{~mm}$. The holotype shows no differences in the shape of the aedeagus with male paratypes from the same data, and shows slightly variations in the shape of paramere and ventral plate (Figs 7-10, 13-16, 19-22) with other male paratypes from Guangxi, Fujian, and Hunan. Geographical differences of male genitalia were also reported by Prokofiev (2014) and Huang \& Wang (2019) in Anomala densa Arrow, 1917, Anomala aureoflava Arrow, 1917, and Anomala trochanterica Arrow, 1917. Two male paratypes from Guangxi and Hunan show more bronze reflections on the pronotum, and male paratype from Fujian shows majority of brown color on elytra.

FEMALE. Length $12.2-13.9 \mathrm{~mm}$, width $8.2-8.6 \mathrm{~mm}$. Females paratypes are distinctly different from males in appearance at first glance as: 1) body predominantly larger than males; 2) body color reddish brown, pronotum with weakly metallic green or copper (strongly in paratypes from Sichuan), elytra obscured by greenish metallic luster (strongly in paratypes from Sichuan), legs dark reddish brown with weakly green reflections; terminal tooth of protibia rather long, apex broad rounded.

DIAGNOSIS. Anomala huangjianbini sp. n. is rather similar to A. vitalisi from Laos, Vietnam and Yunnan (see remarks of $A$. vitalisi) in appearance and male genitalia (Zorn et al., 2017), but it can be distinguished from A. vitalisi (Figs. 28, 29) in males by: 1) surface of scutellum densely transverse punctate, punctures partly coalescent and rugoso-punctate (slightly small and shallow punctures in A. vitalisi); 2) terminal tooth of protibia gradually shrink (apex slightly widened in A. vitalisi); 3) subsutural interstice of elytra broad, gradually narrowed in posterior $1 / 2$, with rather large and deep punctures, almost all the punctures adjacent to each other horizontally; 4) surface of elytra general coarse at first glance; 5) ventral plate of male genitalia with two short furcations (Figs. 7-10), apex of ventral plate nearly invisible in lateral view (Figs. 19-22), lateral margin of paramere bent gradually in the middle (Figs 7-10), both paramere narrowed (Figs. 13-16); 6) metatibia stronger. The specimens illustrated in Lin (2002: figs 25-582) should be conspecific with Anomala huangjianbini sp. n., and the distributions in Guizhou need father specimens to confirm.

HABITAT. Two female specimens of this new species were captured by author using a high net from the tall trees of Ligustrum on the Jinfoshan Mountain at altitude $1200 \mathrm{~m}$.

DISTRIBUTION. China: Chongqing, Sichuan, Hunan, Fujian, Guangdong, Guangxi (Fig. $30)$.

ETYMOLOGY. The new species is named after Jian-Bin Huang from Fujian (China), who provided one male paratype from Fujian province.

\section{Anomala vitalisi Ohaus, 1914}

Figs 5, 6, 11, 12, 17, 18, 23, 24, 28, 29

Anomala vitalisi Ohaus, 1914: 207, fig. 207 (description); Machatschke, 1957: 49 (catalogue); Paulian, 1959: 58, figs. 233-234 (redescription); Machatschke, 1972: 112 (catalogue); Lin, 2002: 410 (records); Zorn \& Bezdék, 2016: 340 (catalogue); Zorn et al., 2017: 349 (records). 
MATERIAL EXAMINED. China: Yunnan, Lvchun County, Honghe, 20.IV 2019, 12 19ㅇ, leg. Zi-Chun Xiong; Yunnan, Xinping, Mt. Ailaoshan, 11-13.V 2016, 1ðे, leg. Lu Qiu (CMZZ); Yunnan, Lincang, Cangyuan County, Nangunhe River, Wengding Protection Station, $1800 \mathrm{~m}, 1-6 . \mathrm{V} 2019,2{ }^{\lambda}, 2$ ㅇ, leg. Yu-Chen Zheng (CMZZ).

DISTRIBUTION. China (Yunnan); Vietnam, Laos (Fig. 30).

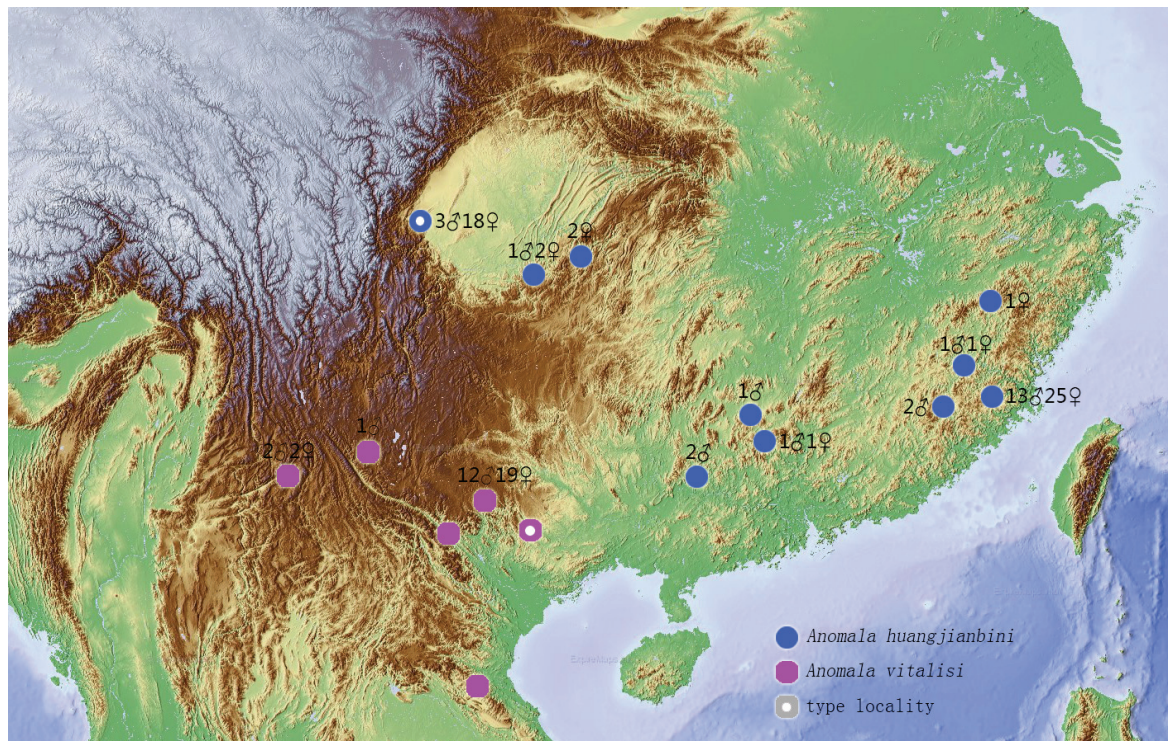

Fig. 30. Distribution of Anomala huangjianbini sp. n. and A. vitalisi which including records from Laos in Zorn et al. (2017).

REMARKS. Anomala vitalisi was recorded from China (Lin 2002; Zorn \& Bezdék 2016; Zorn et al., 2017), Laos (Zorn et al., 2017), and Vietnam (Ohaus, 1914; Machatschke, 1957; Paulian, 1959; Machatschke, 1972; Zorn \& Bezdék 2016; Zorn et al., 2017). Actually, Lin (2002) and Zorn \& Bezdék (2016) provided Chinese provinces records (Fujian, Guangdong, Guizhou, Jiangxi, Sichuan) without father data, and Zorn et al. (2017) only examined a female specimen from 'Canton' (Guangzhou, Guangdong) of South China, the distribution limits of $A$. vitalisi within China can't be certain in these works. In this study, specimens collected from Chongqing, Fujian, Guangdong, Guangxi, Hunan, and Sichuan are definitely not $A$. vitalisi, but $A$. huangjianbini sp. n. In this study, only thirty new specimens from Lvchun County of Yunnan (new distribution record) which exactly matched its original description in Ohaus (1914) were collected from the same mountain range with its type locality: Lao Cai, North Vietnam (160 km away from Luchun County).

\section{ACKNOWLEDGMENTS}

I thank to Jian-Yue Qiu and Hao Xu (Mianyang, China), Jian-Bin Huang (Fujian, China), Zhao-Yang Tang (Guangdong, China) and Ming-Zhi Zhao (Zhuhai, China) for providing Rutelinae materials for this study generously. 


\section{REFERENCES}

Huang, G.Q. \& Wang, F.L. 2019. Two new and one newly recorded species of Anomala Samouelle, 1819 from Yunnan, China. Zootaxa, 4706(2): 366-374. DOI: https://doi.org/ 10.11646/zootaxa.4706.2.9

Lin, P. 2002. Rutelidae. P. 387-427. In: Huang, B. (Ed.): Fauna of insects of Fujian Province of China. Volume 6. Fujian Science \& Technology Press, Fuzhou. 894 pp. [In Chinese and English]

Machatschke, J.W. 1957. Coleoptera Lamellicornia Fam. Scarabaeidae Subfam. Rutelinae. Zweiter Teil. In: Wytsman, P.A.G. (Ed.): Genera insectorum. Fascicule 199 (B). DesmetVerteneuil, Bruxelles. 219 pp.

Machatschke, J.W. 1972. Scarabaeoidea: Melolonthidae, Rutelinae. Coleopterorum Catalogus, Supplementa 66 (1). 's-Gravenhage (W. Junk). 361 pp.

Ohaus, F. 1914. XV. Beitrag zur Kenntnis der Ruteliden. Entomologische Zeitung, 5: $193-$ 217.

Paulian, R. 1959. Coléoptères Scarabéides de 1'Indochine (Rutélines et Cétonines) (suite). Annales de la Société Entomologique de France, 128: 35-136.

Prokofiev, A.M. 2014. New and noteworthy scarab beetles from Asia and America (Coleoptera Lamellicornia). Calodema, 330: 1-25.

Zorn, C. \& Bezděk, A. 2016. Subfamily Rutelinae. P. 317-358. In: Löbl, I. \& Löbl, D. (Eds), Catalogue of Palaearctic Coleoptera. Volume 3. Scarabaeoidea - Scirtoidea Dascilloidea - Buprestoidea - Byrrhoidea. Brill, Leiden, Boston.

Zorn, C. \& Kobayashi, H. \& Wada, K. 2017. Notes on the genus Anomala Samouelle, 1819 (Coleoptera, Scarabaeidae, Rutelinae) in Vietnam and neighboring regions: eight new species and faunistic records. Contributions to Entomology, 67(2), 325-352.

(C) Far Eastern entomologist (Far East. entomol.) Journal published since October 1994.

Editor-in-Chief: S.Yu. Storozhenko

Editorial Board: A.S. Lelej, S.A. Belokobylskij, M.G. Ponomarenko, V.A. Mutin, E.A. Beljaev, E.A. Makarchenko, A.V. Gorochov, T.M. Tiunova, M.Yu. Proshchalykin, S.A. Shabalin, V.M. Loktionov

Address: Federal Scientific Center of the East Asia Terrestrial Biodiversity (former Institute of Biology and Soil Science), Far East Branch of the Russian Academy of Sciences, 690022, Vladivostok-22, Russia.

E-mail: storozhenko@biosoil.ru web-site: http://www.biosoil.ru/fee 